\title{
Descriptive Analysis of the \\ Department of Health-Medical Assistance Program Utilization at the University of the Philippines- Philippine General Hospital from January to June 2018
}

\author{
Christopher G. Manalo and Scarlett Mia S. Tabuñar \\ Department of Emergency Medicine, College of Medicine and Philippine General Hospital, University of the Philippines Manila
}

\begin{abstract}
Objective. The objectives of this paper were to describe and analyze the utilization of the Department of HealthMedical Assistance Program (DOH-MAP) at the University of the Philippines-Philippine General Hospital (UP-PGH) in order to provide actual data on its implementation and to give recommendations on future enforcement.
\end{abstract}

Methods. Clinical and fiscal records of DOH-MAP recipients were prospectively tracked and analyzed from January to June 2018.

Results. A total of Php 20,875,291.98 was utilized in the program from January to June 2018. The departments of Medicine (29.68\%), Surgery (26.25\%), and Neurosciences (15.99\%) were identified as the clinical departments with the highest allocation of assistance fund. The pharmacy (64.28\%), laboratory (12.87\%), and outsourced medical equipment and services from EQUILIFE (10.26\%) were determined to be the cost centers with the highest allotment.

Conclusion. The clinical departments and cost centers with high funding utilization identified in this study are recommended to be given appropriate increase in budget allocation, equipment procurement, maintenance and enhancement, and service improvement in order to provide a comprehensive health service delivery for patients of UP-PGH.

Key Words: health expenditure, healthcare financing, medical assistance

\section{INTRODUCTION}

The major thrust of the Universal Health Care (UHC) agenda 2010-2016 was to improve access to quality hospitals and health facilities under the Health Facility Enhancement Program (HFEP) complemented by the Medical Assistance Program (MAP) in order to assist the underprivileged and indigent patients. In 2014, the Department of Health (DOH) allocated Php3.19 billion for MAP, intended to provide medical assistance to poor patients seeking consultation, rehabilitation, and examination or otherwise confined in government hospitals. ${ }^{1}$ MAP was made available to the University of the Philippines-Philippine General Hospital (UP-PGH) and to all DOH-retained hospitals [e.g., Philippine Heart Center, West Visayas State University Hospital] and local government unit (LGU) hospitals [e.g., Quezon City General Hospital, Sampaloc District Department of Emergency Medicine Philippine General Hospital

University of the Philippines Manila

Taft Avenue, Manila 1000, Philippines

Email: cgmanalo@up.edu.ph Hospital, and San Juan Medical Center]. The University of the Philippines-Philippine General Hospital (UP-PGH) 
signed a memorandum of agreement (MOA) with $\mathrm{DOH}$ on August 2014, for PGH to provide medical assistance to eligible patients under the DOH Administrative Order 2014-0017 guidelines on MAP. ${ }^{2}$ In 2015, UP-PGH was allotted Php93,706,198.00 for the program. As of May 2016, Php49,035,826.68 or 52\% of the 2015 allocation, was utilized. ${ }^{3}$

The total health expenditure (THE) of the Philippines from 2005 to 2011 more than doubled, from P198.4 billion to Php431 billion. ${ }^{4}$ The upward trend continues to significantly grow at a $10.4 \%$ increase, from Php530 billion in 2013 to Php585 billion in 2014. THE comes from four major sources: government; social insurance; private sources; and rest of the world. The bulk of THE consistently come from private sources (private out-of-pocket), accounting for more than half of the expenditures since a decade ago. In 2014, an astounding $68 \%$ of THE emanated from private sources, followed by government spending (17\%), social insurance (14\%) and rest of the world (1\%). ${ }^{5}$ The total health expenditure as a percentage of Gross National Product (GNP) was one of the health care financing indicators set by DOH in the Health Care Financing Strategy (HCFS) goals for 2010-2020, which was surpassed by $4.6 \%$ in $2014 .^{5}$

The poverty incidence, the proportion below the poverty line among Filipinos in 2015 to the total population, was estimated at $21.6 \%$. This was significantly lower than the 2012 statistics which was 25.2\%. A family of five in 2015 needed at least Php6,329 on the average every month, to meet the family's basic food needs, and Php9,064 on the average every month, to meet both basic food and non-food needs. These amounts represent the monthly food threshold and monthly poverty threshold, respectively. There was an increase of 15\% in food and poverty threshold from 2012 to 2015. This translates to about 3.8 million poor Filipino families in the same year ${ }^{6}$, putting an invariable strain to the government to meet the non-food needs, like health, for the marginalized sector.

The Philippine Statistics Authority (PSA) reported in 2014 a per capita health expenditure of $\mathrm{Php} 5,859$ which is up 8.5\% from Php5,400 in 2013, which what every Filipino spends for health. ${ }^{7}$ In 2010, the Philippines ranked $4^{\text {th }}$ among the nine-member ASEAN countries after Singapore, Malaysia and Thailand on per capita health expenditure. ${ }^{8}$ National government efforts to improve health service delivery can be seen on several DOH programs [e.g., health facilities enhancement program, modernization of regional hospitals, provision of premium subsidy for indigents enrolled in the National Health Insurance Program (NHIP) and Department of Social Work and Development (DSWD) program on conditional cash transfer (CCT) program] to address health conditions of those belonging to the poorest segment of the population. ${ }^{4}$ To further augment assistance to indigent patients' access to government hospitals, $\mathrm{DOH}-\mathrm{MAP}$ was initiated to finance the medical needs of eligible individuals.
Benefits from a medical assistance program are multipronged as it can affect various stakeholders which include, more than the indigent patients, the government hospitals downloaded with the funds, medical practitioners, central health bodies e.g. DOH and health policy makers. The increased inflow of financial assistance would likely increase the number of patients accessing government facilities coupled with a raised awareness of the existence of the medical fund resulting to an escalated patient demand in terms of quality and quantity of medical care provided. This in turn would challenge hospitals and health care providers to meet such demands that would ultimately place a greater overall strain to the system. Hospitals will be obligated to provide needed diagnostics, medical supplies, and laboratory tests and ensure regular upkeep of equipment to be able to receive continuous allocation of the assistance fund. Government hospital staff and other related paramedical services will be required to offer reliable and quality coverage in high acuity units particularly the frontline services (e.g., emergency department), the surgical and mostly visited departments (e.g. maternity and surgical departments), and lastly support staff (e.g., nursing, paramedical and administrative personnel) have to be abreast with the pace of the development and demand. The ensuing efforts from all healthcare sectors to fulfill the preconditions of being a regular recipient of the fund will have positive impact to the delivery of care to government hospitals which are notoriously but unfairly known for substandard services. The beneficial or adverse result of the program have to be therefore frequently monitored and evaluated to guide health policy lawmakers in their decisions regarding terminating, supporting or institutionalizing the continued fund allocation for the program. The success of the program will eventually rely on the sustainability of the entire mechanisms involved, namely financial, workforce and feedback tools.

UP-PGH, as a recipient of the DOH-MAP funds, is committed to accomplish its role as partner of government in nation-building by providing quality health care to underprivileged and underserved patients.

Establishing itself as a leading tertiary health facility and training hospital in the country, it is also committed to good governance and transparency. It is therefore of interest to provide evidence on the rationale and utilization of the DOH-MAP by way of a preliminary evaluation in its implementation. This evaluation ultimately aimed to provide data needed in forecasting the hospital's actual requirements with regards equipment, supplies, workforce and infrastructure to improve health service delivery in UP-PGH. The main end user of this evaluation would be the administrators of UP-PGH which include the hospital director and deputy director for fiscal services. Other concerned departments, offices and units of the hospital e.g., Clinical departments, Medical Social Services, Health Operations and Accounting services, would also benefit from the results of this paper. Secondary target users 
include the Central Office of the Department of Health incharge of DOH-MAP nationwide. Eventually the national government officials, including lawmakers, would get a better understanding of MAP program when allocating annual budget for the program.

The main objectives of the study were to describe and analyze the implementation and utilization of the $\mathrm{DOH}-$ MAP at the UP-PGH for a six-month period (from JanuaryJune 2018) in order to provide data to improve its health service delivery. Furthermore, the study aimed to determine the number and percentage of patients who availed of $\mathrm{DOH}-$ MAP, to describe the profile of patients, to determine the total DOH-MAP expenditure per month, to identify which cost centers utilized DOH-MAP, and to determine which clinical departments in UP-PGH availed of DOH-MAP.

\section{MATERIALS AND METHOD}

The evaluation was a prospective tracking of records. The review covered all patient records, electronic and printed, that were available at the Medical Social Service and DOH-MAP offices at UP-PGH, from 01 January through 30 June 2018. Actual data collected were limited to two months (May and June) because the appropriation of the DOH-MAP funds for the year 2018 started only in May 2018. There were no MAP appropriations and disbursement data in January through April 2018 at the time of data collection.

All data, quantitative and qualitative were collected and analyzed using Microsoft Excel. Data were encoded using a password-protected Microsoft ${ }^{\circledR}$ Excel Version 15.37 for data privacy. No specific patient was identified in this study. Data processing included computation of frequencies, percentages, cross-tabulations and means. Data were summarized using tabular and graphical presentations. Qualitative data collected included cost centers and clinical departments that were coded and analyzed using basic level qualitative content analysis framework for the purpose of classification, tabulation, and summarization. Looking for commonalities and patterns could provide more in-depth insight that would support results of the quantitative data e.g. frequency distribution gathered.

The study proposal was submitted to the University of Philippines Manila-Philippine General Hospital Expanded Hospital Research Office (UP-PGH EHRO) and to the University of the Philippines Manila Research Ethics Board (UPM REB) for ethical approval.

The principal evaluator was a resident physician currently training in UP-PGH. There was no conflict of interest arising from financial, familial, or proprietary considerations of the principal investigator, co-investigator, sponsors, or study site.

\section{RESULTS}

In the fiscal year of 2018, the DOH-MAP appropriation and disbursement for UP-PGH started on the month of
May. The total amount of DOH-MAP utilized for the patients of UP-PGH was Php20,875,291.98 (Table 1).

Table 1. Total Expenditure per Month of DOH-MAP

\begin{tabular}{ccc} 
Month & $\begin{array}{c}\text { Number of patients who } \\
\text { availed of DOH-MAP }\end{array}$ & Total Expenditure \\
\hline May & 50 & $4,032,199.27$ \\
June & 206 & $16,843,092.71$ \\
\hline Total & 256 & $20,875,291.98$ \\
\hline
\end{tabular}

A total of 256 patients availed of the DOH-MAP funds. For the month of May, only 50 patients in both the in- and out-patient units of the hospital were covered. This figure quadrupled on the succeeding month of June with 206 patients. Appropriation and disbursement for the fiscal year 2018 started on May. This explains the low utilization for that month. Pediatric patients comprised $16 \%$ of all the patients. Twenty-two percent (22\%) (57/256) were 4150 years old. More than half $(51 \%)$ of the patients were females. The patients' social classification, as determined by the PGH Medical Social Service (MSS) unit, who availed of the medical assistance program were Class D. This class is the lowest in the MSS social strata. The classification was important to determine indigency of patients who are financially challenged to support their medical needs. About $63 \%$ of the patients were unemployed. Another 23\% of the patients were employed but the income appeared to be unable to support basic medical needs. Majority of employed patients were drivers, house helpers, farmers, vendors, and business helpers. This further characterized the profile of underprivileged patients who needed financial support to meet their medical needs (Table 2).

The evaluation of the DOH-MAP in this paper introduced the inclusion of cost centers and clinical departments where the funds were disbursed as useful indicators for efficient delivery of medical assistance. In terms of clinical departments, more than half $(56 \%)$ of the funding was utilized for patients seen in the in-patient and out-patient units of the department of Medicine (29.68\%) and Surgery (26.25\%). Another $44 \%$ of the funding was granted for patients under the following clinical departments: Neurosciences, Pediatrics, Obstetrics and Gynecology, Otorhinolaryngology, and Family and Community Medicine. Clinical units with minimal funding received were for Cancer Institute, Rehabilitation Medicine, Orthopedic Surgery, and Ophthalmology and Visual Sciences (Figure 1).

The departments of Medicine, Surgery, Neurosciences, Pediatrics, and Obstetrics and Gynecology collectively summed up approximately $93 \%$ of all fund allocation. Patients of the Department of Medicine (29.68\%) received the largest percentage of the funds. Patients under this clinical department were mostly with critical conditions e.g., respiratory failure, and septic and cardiogenic shock. This subset of patients had extensive medical needs during the course of their admission e.g., mechanical ventilation, 
Table 2. Sociodemographic data of Patients who Availed of DOH-MAP per Month

\begin{tabular}{|c|c|}
\hline & $\begin{array}{l}\text { Number of patients who } \\
\text { availed DOH-MAP }(n=256)\end{array}$ \\
\hline \multicolumn{2}{|l|}{ Age Range } \\
\hline$<18$ & 42 \\
\hline $19-30$ & 39 \\
\hline $31-40$ & 22 \\
\hline $41-50$ & 57 \\
\hline $51-60$ & 46 \\
\hline $61-70$ & 33 \\
\hline $71-80$ & 14 \\
\hline$>81$ & 2 \\
\hline \multicolumn{2}{|l|}{ Gender } \\
\hline Male & 125 (49\%) \\
\hline Female & $131(51 \%)$ \\
\hline \multicolumn{2}{|l|}{ MSS Classification* } \\
\hline Class A & 0 \\
\hline Class B & 0 \\
\hline Class C & 0 \\
\hline Class D & $256(100 \%)$ \\
\hline \multicolumn{2}{|l|}{ Employment Status } \\
\hline Unemployed & 160 (63\%) \\
\hline Employed & $60(23 \%)$ \\
\hline Driver & 12 \\
\hline House helper & 8 \\
\hline Farmer & 6 \\
\hline Vendor & 5 \\
\hline Business helper & 4 \\
\hline Carpenter & 3 \\
\hline Security Guard & 3 \\
\hline Office Clerk & 2 \\
\hline Construction Worker & 2 \\
\hline Others^^ & 15 \\
\hline
\end{tabular}

* Based on Medical Social Service classification of patients

^ Others include bank teller, garbage collector, barangay worker, plumber, dress maker, government employee, sales manager, longshoreman, bagger, aircon technician, technician, Overseas Filipino Worker, tattoo artist, teacher, and warehouseman

intravenous medications especially antibiotics, critical care equipment needed for hemodynamic monitoring, and cardiovascular procedures. A great majority of these patients were admitted in the intensive care unit. Patients from the Department of Surgery (26.25\%) ranked second among patients who received the assistance fund. These patients had substantial expenditure on pharmaceuticals, operative interventions e.g. operating room, anesthetic equipment, post-anesthesia care unit, and surgical intensive care unit charges. Majority of surgical patients had multiple traumatic injuries and significant burns. This group of patients included both pediatric and adult population. Ranking third among the recipients of the fund were patients of the Department of Neurosciences (15.99\%). Considerable amount was spent on thrombolysis in patients with hyper-acute ischemic stroke and intravenous immunoglobulin administration in patients with Guillain-Barré Syndrome under the section of Neurology while substantial amount was spent on the medical and surgical management of severe traumatic brain injuries and subarachnoid hemorrhage under the section of Neurosurgery. Fourth on the list were patients from the
Department of Pediatrics (15.71\%) with critical conditions such as shock, congenital heart disease such as ventricular septal defect, and malignancies. Intravenous immunoglobulin was also given to pediatric patients with measles, atypical Kawasaki Disease, and anti-NMDA receptor encephalitis. Majority of the pediatric patients were managed medically at the pediatric intensive care unit. The last cluster of patients which composed the majority of expenditure was from the Department of Obstetrics and Gynecology (5.22\%). Noteworthy funding was allotted to diagnostics, medical, and operative management of gynecologic conditions e.g., cervical and ovarian malignancies.

In total, 64.28\% (Php13.161 million) of the funds covered pharmaceutical needs. Pharmaceutical items included all medications used for patients in both in-patient and out-patient units. Expenditure on laboratory tests (12.87\%), EQUILIFE mechanical ventilators, and breathing equipment (10.26\%), radiology (3.60\%), cardiovascular unit $(3.742 \%)$, and intensive care units (1.35\%) made up the majority of the fund use. These cost centers inclusively comprised $90 \%$ of all fund disbursements. Equipment and services under EQUILIFE (i.e., mechanical ventilators, bi-level positive airway pressure equipment, continuous positive airway pressure equipment) were outsourced from EQUILIFE Medical Equipment Supplies and Services Incorporated. Allocation on pharmaceuticals included a wide array of medications ranging from intravenous antibiotics, intravenous thrombolytics, to intravenous immunoglobulins. These made up a congregate of expensive medications administered to the recipients of the funds. Pharmaceutical items were consistently given the highest allocation across all clinical departments in both in-patients and out-patient facilities. The laboratory (12.87\%) was the second cost center with the highest expenditure. Like pharmaceuticals, laboratory tests were a mainstay assemblage of expenditure in both in-patient and out-patient services. Worthy of attention was the Medical Research Laboratory specifically the immunologic tests. These were very important tests ordered for accurate diagnosis but were relatively costly. EQUILIFE equipment and consumables (10.26\%) were third on the list of cost centers with the highest allocation. This cost center provided equipment and consumable items for mechanical ventilators and bi-level positive airway devices. As discussed, majority of adult and pediatric patients in the intensive care units whether medically or surgically managed needed airway and ventilatory support. This resulted to particularly high pay out on the equipment and consumable items outsourced from the EQUILIFE Medical Equipment Supplies and Services Incorporated. Radiology (3.60\%) and Cardiovascular (3.07\%) units were the fourth and fifth on the list of cost centers with the highest allocation. Funds for the Radiology cost center were spent on imaging modalities such as magnetic resonance imaging, computed tomography, and bone scanning, and radioactive procedures like cobalt therapy. Lastly, majority of funds on the cardiovascular 


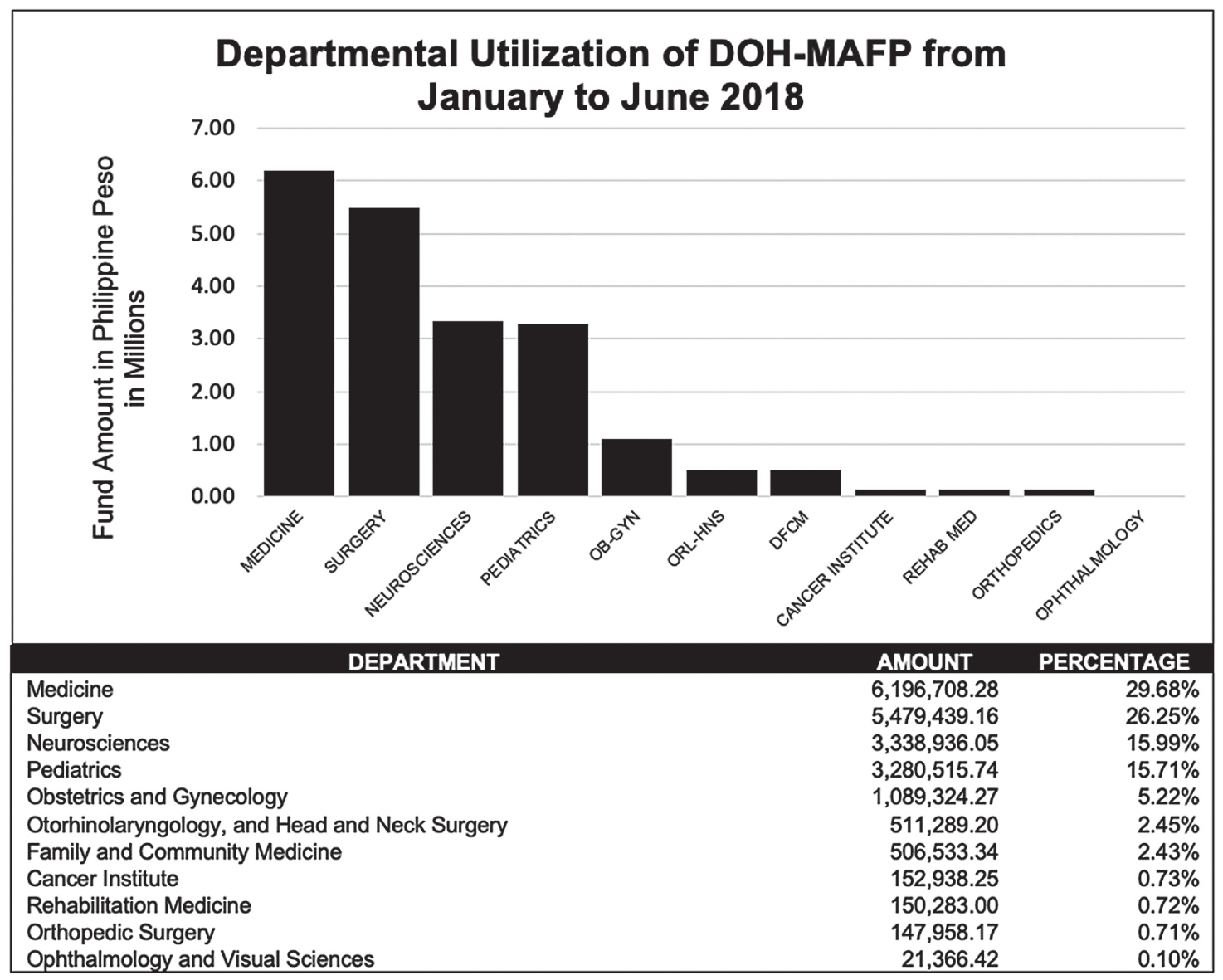

Figure 1. Clinical Department Utilization of the DOH-MAP from January to June 2018.

unit was disbursed for cardiac catheterization and cardiac imaging procedures for patients with acute ST-segment elevation myocardial infarction and two- to three-vessel coronary artery disease (Table 3 ).

\section{DISCUSSION}

The analysis revealed that additional support in terms of operating expenses and manpower augmentation are necessary for the clinical departments and cost which largely utilized the fund. Accordingly, upgrading of the facilities and equipment in the diagnostic centers like Radiology and Laboratory Departments are essential to continually provide standard of care. The increasing number of patients has an adverse consequence to these units in the hospital. The added stress in keeping up with the expectations of the stakeholders and ballooning workload will definitely take its toll to the workforce in the long run. If these are not adequately addressed, the consistency and viability of the health services is compromised.

This paper is a preliminary analysis of the DOH-MAP implementation in PGH. A number of limitations were identified: a unified electronic data gathering specifically for this fund in order to have a regular and accurate reporting for the hospital and $\mathrm{DOH}$ administrators to analyze and get a better perspective of the MAP utilization is still not present; actual per patient utilization cannot be obtained as it is not particularly noted by MSS or by the ISO; a standardized documentation should be initiated to integrate all information gathered; and lastly, clinical guidelines or protocols must guide MAP handlers on the amount of support to be given to each beneficiary. Although MAP may have attained one of its goals of reaching the poorest among the poor to avail of health services, modifications and further evaluation may still be needed to conclude if its target long term effects of better health outcomes in terms of health indicators e.g., reduced mortality and morbidity, are achieved.

The laudable objective of the government in assisting the poor indigent patients of government hospital is the driving force in the implementation of DOH-MAP. It aims to make health services affordable and accessible to the marginalized sectors of society who make up majority of patients in public medical facilities. This evaluation revealed that it partly achieved its intent of reaching the target recipients of the program as more than $50 \%$ of those consulting at the Emergency Department were able to avail of financial support. Though the assistance program has some initial gains in its enforcement, the following initiatives and strategies are 
Table 3. Cost Center Utilization of the DOH-MAP from January to June 2018

\begin{tabular}{lrr}
\hline Cost Center & \multicolumn{1}{c}{ Amount } & Percentage \\
\hline Pharmacy & $13,161,332.33$ & $64.2836 \%$ \\
Laboratory & $2,635,420.10$ & $12.8721 \%$ \\
EQUILIFE Equipment \& Consumable & $2,101,494.68$ & $10.2643 \%$ \\
$\quad$ Items* & & \\
Radiology & $738,688.50$ & $3.6080 \%$ \\
Cardiovascular Unit & $629,407.20$ & $3.0742 \%$ \\
Intensive Care Units & $276,440.00$ & $1.3502 \%$ \\
Operating Room & $198,080.00$ & $0.9675 \%$ \\
Anesthesia \& Post-anesthesia Care & $186,039.50$ & $0.9087 \%$ \\
$\quad$ Unit & & \\
B. Braun & $132,315.00$ & $0.6463 \%$ \\
Pulmonary Medicine & $112,840.00$ & $0.5511 \%$ \\
Blood Bank & $95,760.00$ & $0.4677 \%$ \\
CENDU & $58,290.25$ & $0.2847 \%$ \\
Hemodialysis Unit & $37,395.00$ & $0.1826 \%$ \\
Ear Unit & $28,540.00$ & $0.1394 \%$ \\
Cobalt & $28,170.00$ & $0.1376 \%$ \\
Hematology & $17,347.00$ & $0.0847 \%$ \\
Electrocardiography (ECG) Unit & $10,454.00$ & $0.0511 \%$ \\
Electroencephalography (EEG) Unit & $7,600.00$ & $0.0371 \%$ \\
Obstetrics \& Gynecology Sonography & $6,700.00$ & $0.0327 \%$ \\
Thoracic Cardiovascular Surgery & $6,000.00$ & $0.0293 \%$ \\
Supplies (e.g. masks) & $2,200.00$ & $0.0107 \%$ \\
Photon Blood & $1,800.00$ & $0.0088 \%$ \\
Newborn Screening & $1,550.00$ & $0.0076 \%$ \\
Kits & 50.00 & $0.0002 \%$ \\
\hline & & \\
\hline
\end{tabular}

* Equipment and services such as use of mechanical ventilators, bi-level positive airway pressure machine, and continuous positive airway pressure machine are currently being outsourced to EQUILIFE Medical Equipment Supplies and Services Incorporated.

recommended to be able to sustain its achievements in tertiary government hospitals like PGH in terms of legislation, work force complement, documentation, provisions for health packages, and patient engagement: 1) Financial assistance fund for poor patients should be institutionalized thru congressional legislation so that an allocated funding will be guaranteed in the annual government budget; 2) Part of the fund should be appropriated to personnel services, operating expenses and facility upgrade, as provision of care cannot just rely on supplies, medicines and tangible health resources; 3) Workforce welfare that will deliver the needed services should be factored in the equation; 4) Equipment upkeep should be considered to endure the taxing additional load in service provision; 5) An integrated electronic documentation of patients availing of the fund must be initiated to link other hospitals in the system for it is essential to accurately assess the program implementation; 6) Standardization of data collection based on accepted and evidenced-based clinical protocols should be the norm to be able to track actual patient care, guide monetary award and monitor eventual outcome of patients.
As diseases become more complex needing different interventions, the proven clinical guidelines will streamline decision making not only on the part of the clinician but also on the administrators and MAP managers. This will help trail if the financial assistance was also able to provide improvement in the patient's condition which is the ultimate aim of the program. Health packages with specified amounts can be set to regulate monetary assistance and avoid abuse by both clinician and patients.

Funds must not only be directed to tertiary care; similar assistance programs must also be channeled to primary and secondary health institutions to also improve capabilities of these hospitals that focuses on preventive and health promotion activities. This in effect will be more economical and cost effective for the government and health sector as a whole.

Patients must also be engaged in the decisions about their health care. The culture of dependency must be carefully weighed against the real need for medical care. Patients must also be encouraged to actively take part in their health management by being financially protected. This can be achieved by consciously exerting effort to save up for future medical expenses e.g. paying premiums for Philhealth or by having healthy lifestyles and avoiding risky behavior.

\section{CONCLUSION}

In this paper, the utilization of the DOH-MAP in the University of the Philippines-Philippine General Hospital in terms of total expenditure, profile of patients, cost centers, and clinical departments from January to June 2018 was evaluated and presented. The departments of Medicine, Surgery, and Neurosciences were identified as the clinical departments with the highest allocation of assistance fund. The pharmacy, laboratory, and EQUILIFE machines and consumable items were the cost centers with the highest allotment of assistance fund. The clinical departments and cost centers with high funding utilization identified in this study are recommended to be given appropriate fund increases with regards budget allocation, equipment procurement, maintenance and enhancement, and service improvement in order to provide a comprehensive health service delivery.

It is also recommended that a summary of the patients' profiles, cost centers, and clinical departments where funding were utilized be included in the program report in a central repository of data in order to track and evaluate the implementation of the program and to project patients' needs.

\section{Statement of Authorship}

All authors participated in the data collection, analysis, and final approval of the study.

\section{Author Disclosure}

All authors declared no conflicts of interest. 


\section{Funding Source}

This paper was funded by the Philippine General Hospital 2018 Research Grant for Residents and Fellows.

\section{REFERENCES}

1. Department of Health. Implementing Guidelines on the Medical Assistance Program (MAP) of the Department of Health. May 2014.

2. AO 2014-017 Department of Health. AO No. 2014-017 Implementing Guidelines on the Medical Assistance Program (MAP) of the Department of Health. Manila : s.n., May 22, 2014.

3. Philippine General Hospital. Preliminary Accomplishment Report. Manila : s.n., 2016.
4. Sabornido N. Health Sector Budget: An Analysis. s.l. : Legislative Budget Research and Monitoring Office (BRMO), Senate of the Philippines, 2013.

5. Garcia R, Sabenano RD. Each Pinoy Spent 5,859 for health in 2014. s.l.: Philippine Statistics Office, 2016.

6. Perez J. Poverty incidence among Filipinos registered at $21.6 \%$ in 2015-PSA. s.1.: Philippine Statistics Authority, 2016.

7. Philippine Statistics Authority. Each Pinoy Spent 5,859 for health in 2014. Oct 2016. National Health Accounts 2016.

8. ASEAN Health Policy Series Part 1: Introduction to ASEAN Health Systems presented e ISPOR 20th International Meeting in Philadelphia. Ngorsuraches, Surachat. 2015. News Across Asia. Vol. 4.

The Acta Medica Philippina is now accepting original scientific papers, review articles and case reports for its upcoming issues. Please follow the format for submission as indicated in the "Instructions to Authors" elsewhere in the journal. All papers received shall be properly acknowledged. For inquiries and submission of proposals, please email us at actamedicaphilippina.upm@up.edu.ph 